\title{
Pre-surgical Pulmonary Rehabilitation in Asthma Patients Undergoing Bariatric Surgery
}

\author{
Yasemin Türk $^{1}$ (1) Astrid van Huisstede ${ }^{1}$ Pieter S. Hiemstra ${ }^{2}$. Christian Taube ${ }^{2}$. \\ Gert-Jan Braunstahl ${ }^{1}$
}

Published online: 22 August 2017

(C) Springer Science+Business Media, LLC 2017

\begin{abstract}
This pilot study was performed to investigate the feasibility of pre-surgical pulmonary rehabilitation (PR) in morbidly obese patients with uncontrolled asthma, undergoing bariatric surgery. Four morbidly obese female patients with asthma participated in a 12-week PR program (exercise, diet, and psychological intervention) before undergoing bariatric surgery, and the outcomes were compared to a matched group of seven female controls (bariatric surgery only). In patients who participated in PR, asthma control and asthma quality of life improved dramatically after 3 months of PR. Besides, asthma control was better at the moment of surgery. The results of this pilot study show that PR is feasible in morbidly obese asthmatics and should be considered for a
\end{abstract}

Electronic supplementary material The online version of this article (doi:10.1007/s11695-017-2888-y) contains supplementary material, which is available to authorized users.

Yasemin Türk

y.turk@franciscus.nl

Astrid van Huisstede

A.AardenburgvanHuisstede@Franciscus.nl

Pieter S. Hiemstra

p.s.hiemstra@lumc.nl

Christian Taube

christian.taube@ruhrlandklinik.uk-essen.de

Gert-Jan Braunstahl

g.braunstahl@franciscus.nl

1 Department of Pulmonology, Franciscus Gasthuis, Kleiweg 500, 3045 PM Rotterdam, The Netherlands

2 Department of Pulmonology, Leiden University Medical Center, 2300 RC Leiden, The Netherlands selected group of patients with uncontrolled asthma before undergoing bariatric surgery.

Keywords Asthma $\cdot$ Bariatric surgery $\cdot$ Pulmonary rehabilitation

\section{Introduction}

Epidemiological studies have shown that obesity increases the risk of developing asthma, and that asthma in obese people is often associated with more symptoms, a lower peak flow and a higher need of inhalation medication [1]. In a previous study, we have demonstrated that bariatric surgery has a proven beneficial effect on symptoms and lung function in morbidly obese patients with asthma [2]. However, surgery has risk of complications, especially in patients with pulmonary diseases [3]. Furthermore, bariatric surgery does solve the problem of overeating, but it does not address other important issues like behavior or lifestyle. Lifestyle and especially exercise is an important factor in both managing obesity and asthma. Therefore, a debate has emerged whether lifestyle intervention before bariatric surgery can improve the outcomes of bariatric surgery and can decrease the risk of complications in morbidly obese patients with asthma. Pulmonary rehabilitation (PR) can be seen as a lifestyle intervention [4] that is especially suited for patients with obesity-related respiratory disorders and individuals with lung disease in whom obesity is also contributing to functional limitation. Nevertheless, data on the effect of PR in obese patients with respiratory disorders are limited. Therefore, we performed a pilot study to investigate the feasibility of pre-surgical pulmonary rehabilitation aimed to improve the outcomes of bariatric surgery in morbidly obese patients with uncontrolled asthma. 


\section{Materials and Methods}

\section{Study Design}

We performed an explorative case-control study in which we compared morbidly obese female patients with asthma participating in a 12-week PR program before undergoing bariatric surgery with a matched subgroup of our previous study [2]. This subgroup consisted of morbidly obese female patients with uncontrolled asthma (ACQ > 1.5) who did undergo bariatric surgery without PR before. We compared lung function $\left(\mathrm{FEV}_{1}\right)$, body mass index (BMI), asthma control, and asthma quality of life. In the patients that underwent PR before bariatric surgery, exercise capacity was also measured. The total follow-up of the study was 6 months after bariatric surgery. All procedures performed in this study were in accordance with the ethical standards of the institutional and/or national research committee and with the 1964 Helsinki declaration and its later amendments or comparable ethical standards.

\section{Study Population}

The study population consisted of morbidly obese subjects (BMI $>40 \mathrm{~kg} / \mathrm{m}^{2}$ ) with proven asthma. Informed consent was obtained from all individual participants included in the study. Asthma diagnosis was based on the presence of symptoms and reversible airway obstruction or bronchial hyperresponsiveness. Patients were between 18 and 55 years old and had uncontrolled asthma (Asthma Control Questionnaire (ACQ) score of $\geq 1.5$ ) after maximal treatment.

\section{Intervention}

The PR program consisted of 12 weeks of outpatient training, which took place three times a week during 40-60 min. Exercise training was based on a high-intensity interval training (HIIT) protocol and was supervised by a physiotherapist. Participants were allowed to have an intake of maximal $1500 \mathrm{kcal} /$ day. There were four clinical visits and three phone consultations with the dietician. Psychological counseling took place during four group sessions of $1 \mathrm{~h}$. These sessions focused on behavioral modification and motivational strategies. After 12 weeks of rehabilitation, the patients underwent laparoscopic bariatric surgery: either a gastric sleeve gastrectomy or a Roux-en-Y gastric bypass surgery. Controls underwent laparoscopic bariatric surgery without participating in a PR program before. All subjects underwent preoperative screening and consultation of the internist, psychologist, and dietician as a part of standard bariatric care. All candidates were required to lose weight before surgery. In addition, they followed a low-carbohydrate diet during 2 weeks before the planned bariatric surgery to reduce the size of the liver, so the surgery could be performed more easily.

\section{Outcomes}

Outcomes measured in cases and controls were: the asthma symptom score (ACQ), asthma quality of life (AQLQ), BMI, FEV1, and complications. Outcomes measured in the cases only were exercise capacity (6-min walking distance (6MWD), maximal oxygen uptake $\left.\left(\mathrm{VO}_{2 \max }\right)\right)$ and daily step count.

\section{Assessments}

See supplementary material for a detailed description of the questionnaires, lung function tests, and exercise tests. Briefly, validated questionnaires were used to assess asthma control and asthma-related quality of life $[5,6]$. Exercise capacity was measured by a 6 -min walking test and a cardiopulmonary exercise test $[7,8]$. Lung function, bronchial hyperresponsiveness (PD20), and fractional exhaled nitric oxide $\left(\mathrm{Fe}_{\mathrm{NO}}\right)$ were measured according to ERS/ ATS recommendations [9, 10]. All complications within 90 days of bariatric surgery were scored.

\section{Data Presentation}

Categorical data were presented as percentages, and continuous variables were summarized as median values with interquartile ranges (IQR). No statistical analysis was performed due to the low sample size. Follow-up was completed until 6 months post-surgery.

\section{Results}

\section{Patient Characteristics}

Four cases and seven controls were included in the study. Baseline characteristics are shown in Table 1. Both cases and controls were morbidly obese (median BMI $>40 \mathrm{~kg} /$ $\mathrm{m}^{2}$ ). Patients who participated in PR before bariatric surgery were older (44 vs 30 year), had a lower $\mathrm{FEV}_{1}$ (73.5 vs 96\%), and had a worse asthma control (ACQ 2.23 vs 1.86) compared to controls.

\section{Outcomes After 3 Months of PR}

All four cases completed 3 months of PR. The median adherence rate was $80.6 \%$ [77.3-91.3]. There were no adverse events related to the exercise training or other interventions of PR. In all patients, asthma control improved dramatically (median ACQ from 2.23 to 0.59 ) after 12 weeks of PR. Importantly, this improvement was above the minimal clinical importance difference (MCID) of $\geq 0.5$. Besides, the increase in AQLQ was also clinically relevant. There was a decrease in 
Table 1 Baseline characteristics of cases (PR before BS) and controls (BS bariatric surgery)

\begin{tabular}{|c|c|c|}
\hline & $\begin{array}{l}\text { PR before BS } \\
(n=4)\end{array}$ & $\begin{array}{l}\mathrm{BS} \\
(n=7)\end{array}$ \\
\hline Age (y) & $44[28-48]]$ & $30[25-46]$ \\
\hline BMI $\left(\mathrm{kg} / \mathrm{m}^{2}\right)$ & $44.75[41.0-45.59]$ & $45.87[44.32-52.22]$ \\
\hline Waist circumference $(\mathrm{cm})$ & 134.5 [116.3-141.5] & $131.0[121-152.25]$ \\
\hline FFMI & 22.06 [20.44-22.65] & 21.64 [20.24-24.24] \\
\hline FEV1 $(\%)$ & $73.5[58.3-95.5]$ & $96.0[86.0-107.0]$ \\
\hline $\mathrm{FVC}(\%)$ & $102.0[85.75-115.3]$ & $97.0[92.0-116.0]$ \\
\hline $\mathrm{FRC}(\%)$ & $68.00[58.00-105.0]$ & 64.50 [52.25-89.50] \\
\hline RV (\%) & 96.0 [77.50-119.75] & 89.50 [88.25-105.0] \\
\hline $\mathrm{Fe}_{\mathrm{NO}}(\mathrm{ppm})$ & $24.0[6.0-66.75]$ & $12.0[8.0-12.0]$ \\
\hline $\mathrm{EO}\left(\times 10^{\wedge} 9 / 1\right)$ & $0.30[0.25-0.30]$ & $0.10[0.0-0.10]$ \\
\hline ACQ & $2.23[1.66-2.96]$ & $1.86[1.71-2.43]$ \\
\hline AQLQ & $3.79[2.75-5.27]$ & $4.27[3.93-5.07]$ \\
\hline Daily steps & 6901 [6144-8160] & 5705 [3347-7584] \\
\hline $\mathrm{VO}_{2 \max }(\mathrm{ml} / \mathrm{kg} / \min )$ & $14.30[12.15-19.98]$ & \\
\hline $\mathrm{VO}_{2 \max }(\%)$ & $43.0[35.25-55.25]$ & \\
\hline 6MWD (m) & $509[486-545]$ & \\
\hline $6 \mathrm{MWD}(\%)$ & 81.87 [69.23-90.05] & \\
\hline
\end{tabular}

All variables are presented as medians with the interquartile range $B M I$ body mass index (weight $(\mathrm{kg}) /$ height $^{2}(\mathrm{~cm})$ ), FFMI fat free mass index $(\mathrm{kg} / \mathrm{m} 2), F E V_{l}$ forced expiratory volume in $1 \mathrm{~s}, F V C$ forced vital capacity, $F R C$ forced residual capacity, $R V$ residual volume, $F e N O$ fractional exhaled nitric oxide (ppm), $E O$ eosinophil's $\times 10^{\wedge} 9 / 1, A C Q$ asthma control questionnaire, $A Q L Q$ asthma quality of life questionnaire, $\mathrm{VO}_{2} \max$ maximal oxygen uptake, $6 \mathrm{MWD}$ 6-min walking distance

median BMI $\left(\Delta-1.39 \mathrm{~kg} / \mathrm{m}^{2}\right)$. Exercise tolerance measured with the 6-min walking test and cardiopulmonary exercise test improved in all patients (Table 2). The median improvement of 6MWD was above the MCID of $30 \mathrm{~m} \mathrm{[7].}$

\section{Bariatric Surgery}

Cases underwent bariatric surgery within 2 weeks after the last PR session. Compared to controls, cases had better-controlled asthma at the moment of surgery (Fig. 1a). A gastric bypass surgery was performed in three cases and one control, and a gastric sleeve surgery was performed in one case and six controls. In the group of cases, one patient developed a productive cough the day after (gastric bypass) surgery and received a treatment with antibiotics and corticosteroids. The same patient underwent a re-surgery within 30 days after the initial surgery because of an anastomotic leakage. After this re-surgery, she was admitted to the intensive care unit (ICU) because she developed a respiratory failure as a result of aspiration pneumonia. After 1 week of treatment in the ICU, she was able to recover in the surgery ward and was discharged from hospital in good condition. Other cases did not have any complications from the surgery. There were no complications of the surgery in the group of controls.

\section{Outcomes 3 and 6 months After Bariatric Surgery}

Three months after bariatric surgery both in cases and controls ACQ was improved compared to baseline. Although there was some increase in ACQ in cases at 3 months, ACQ remained significant lower until 6 months in both groups compared to baseline (Fig. 1a). Both in cases and controls, AQLQ improved after bariatric surgery (Fig. 1b). Also, there was a large decrease in BMI (Fig. 1c). In cases, there was a gradual improvement of $\mathrm{FEV}_{1}$, but no improvement was seen in $\mathrm{FEV}_{1}$ in controls (Fig. 1d) (Table 3). Exercise tolerance (6MWD) improved further in cases at 3 and 6 months after bariatric surgery, and this improvement was clinically relevant (Fig. 2). However, there was no marked increase in the daily step count (Table 2 ).

Table 2 Outcomes in cases (PR before BS) $(n=4)$

\begin{tabular}{|c|c|c|c|c|}
\hline & $\begin{array}{l}\text { Baseline } \\
(n=4)\end{array}$ & $\begin{array}{l}\text { After PR } \\
(n=4)\end{array}$ & $\begin{array}{l}3 \text { months after BS } \\
(n=4)\end{array}$ & $\begin{array}{l}6 \text { months after BS } \\
(n=4)\end{array}$ \\
\hline BMI $\left(\mathrm{kg} / \mathrm{m}^{2}\right)$ & $44.8[41.0-45.6]$ & $42.7[39.6-44.1]$ & $35.4[30.9-39.3]$ & $30.0[28.1-35.0]$ \\
\hline Waist circumference $(\mathrm{cm})$ & 134.5 [116.3-141.5] & 118.5 [111.8-120.3] & 94.0 [89.8-111.0] & 94.0 [89.8-111.0] \\
\hline ACQ & $2.23[1.66-2.96]$ & $0.59[0.04-2.13]$ & $0.83[0.21-0.96]$ & $0.75[0.08-1.29]$ \\
\hline AQLQ & $3.79[2.75-5.27]$ & $5.12[3.98-6.10]$ & $6.30[5.78-6.82]$ & $6.20[5.39-6.82]$ \\
\hline $\mathrm{FEV}_{1}(\%)$ & $73.5[58.3-95.5]$ & $74.0[59.8-87.5]$ & $76.0[51.3-88.8]$ & $85.0[59.0-92.3]$ \\
\hline $\mathrm{FRC}(\%)$ & $68[58-105]$ & $80[76-80]$ & 103 [67-137] & 102 [79-136] \\
\hline Daily steps & 6901 [6144-8160] & 5305 [4584-5305] & $6283[4176-10,357]$ & 8336 [6067-8336] \\
\hline $\mathrm{VO}_{2 \max }$ & $14.3[12.15-16.98]$ & $15.4[13.1-15.4]$ & & \\
\hline 6MWD (m) & 509 [486.3-544.5] & $541[531-541]$ & $567[524-629]$ & $571[561-621]$ \\
\hline
\end{tabular}

All variables are presented as medians with the interquartile range

$B M I$ body mass index (weight $(\mathrm{kg}) /$ height $^{2}(\mathrm{~cm})$ ), $A C Q$ asthma control questionnaire, $A Q L Q$ asthma quality of life questionnaire, $F E V_{l}$ forced expiratory volume in $1 \mathrm{~s}, F R C$ forced residual capacity, $\mathrm{VO}_{2}$ max maximal oxygen uptake, $6 M W D$ 6-min walking distance 
Fig. 1 a Asthma control (ACQ), b Asthma quality of life (AQLQ), b Body mass index (BMI), and $\mathbf{d}$ Forced expiratory volume in $1 \mathrm{~s}$ $\left(\mathrm{FEV}_{1}\right)$ before and after bariatric surgery in morbidly obese patients with and without presurgical pulmonary rehabilitation (PR + BS vs. BS)
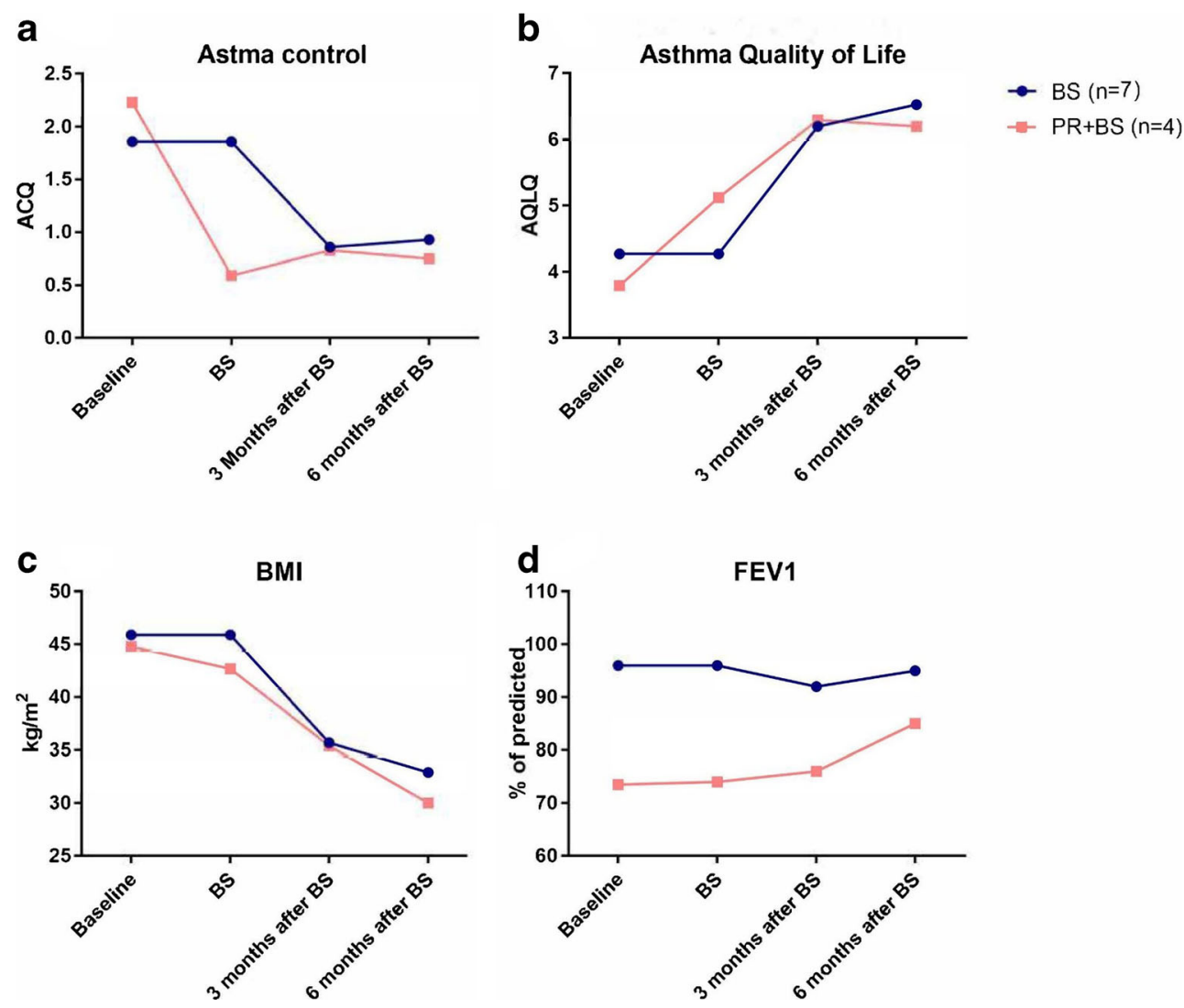

\section{Discussion}

In this explorative study, we included four female obese asthma patients participating in a 3-month pulmonary rehabilitation program before undergoing bariatric surgery. In these patients, we have seen improvements in asthma control, asthma quality of life, $\mathrm{VO}_{2 \max }$, and 6MWD after 3 months of PR. Furthermore, there was a decrease in the median BMI before undergoing bariatric surgery. Importantly, these improvements were clinically relevant. Besides, during 6 months of follow-up after bariatric surgery, the improvements in ACQ, AQLQ, and 6MWD persisted. Compared to a matched subgroup of seven female patients from our previous study who did not participate in a PR program before bariatric surgery, patients who participated in PR were older and had a lower FEV1 and a less controlled asthma. Still, PR was effective to improve asthma control and exercise tolerance before bariatric surgery. Although we were not able to show reductions in complications in this study, we assume that a better asthma control before surgery could result in lower rate of complications. The results of this case-control study suggest that a PR program is feasible and could be beneficial for a selected group of obese patients with uncontrolled asthma before undergoing bariatric surgery.

There is very limited data available about the effect of PR in morbidly obese asthma patients. In a randomized
Table 3 Outcomes in controls (BS only) $(n=7)$

\begin{tabular}{llll}
\hline & $\begin{array}{l}\text { Baseline } \\
(n=7)\end{array}$ & $\begin{array}{l}3 \text { months after BS } \\
(n=7)\end{array}$ & $\begin{array}{l}6 \text { months after BS } \\
(n=7)\end{array}$ \\
\hline BMI $\left(\mathrm{kg} / \mathrm{m}^{2}\right)$ & $45.9[44.3-52.2]$ & $35.7[34.5-48.8]$ & $32.9[30.1-43.8]$ \\
Waist circumference $(\mathrm{cm})$ & $131.0[121.0-152.3]$ & $109.0[107.0-136.0]$ & $99.0[92.0-118.0]$ \\
ACQ & $1.86[1.71-2.43]$ & $0.86[0.21-1.61]$ & $0.93[0.11-1.04]$ \\
AQLQ & $4.27[3.93-5.07]$ & $6.20[5.45-6.60]$ & $6.13[5.90-6.33]$ \\
FEV $_{1}(\%)$ & $96.0[86.0-107.0]$ & $92.0[83.0-93.0]$ & $95.0[77.0-103.0]$ \\
\hline
\end{tabular}

All variables are presented as medians with the interquartile range

$B M I$ body mass index (weight $(\mathrm{kg}) /$ height $^{2}(\mathrm{~cm})$ ), $A C Q$ asthma control questionnaire, $A Q L Q$ asthma quality of life questionnaire, $F E V_{l}$ forced expiratory volume in $1 \mathrm{~s}, F R C$ forced residual capacity 
6MWD

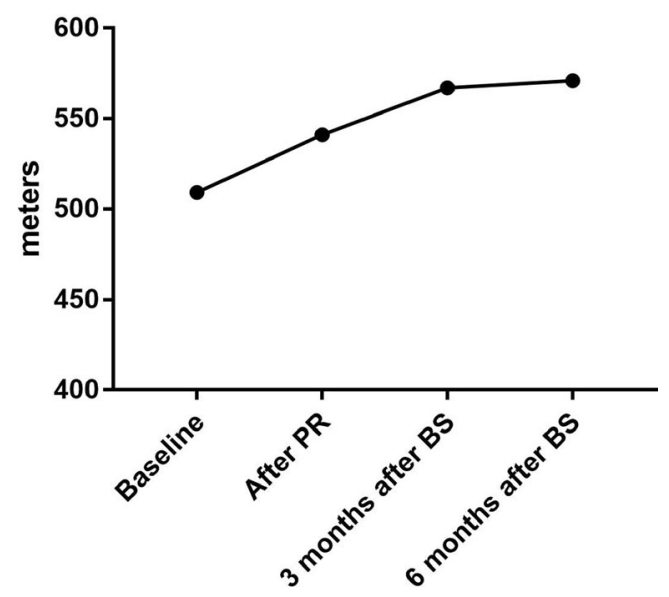

Fig. 2 Six-minute walking distance (6MWD) in morbidly obese patients who participated in PR before bariatric surgery

controlled trial with obese asthmatics, Scott et al. showed that after 10 weeks of either dietary intervention or combined dietary/exercise invention, patients had a significant amount of weight loss. Besides, modest weight loss (5$10 \%$ of body weight) was sufficient to improve asthma control, lung function, and quality of life in obese adults with asthma [11]. Another recent study showed clinical improvements in asthma control, greater weight loss, and improvements in aerobic fitness after a 3-month weight loss program combined with exercise in obese asthmatics [12]. However, patients included in these studies were not morbidly obese as in the present study. Studies about PR in morbidly obese patients with respiratory disorders before undergoing (bariatric) surgery are lacking. Nevertheless, such studies are highly relevant because these patients have an increased risk for developing complications after surgery. A recent randomized controlled trial by Baillot et al. showed that pre-surgical exercise training is feasible in subjects with obesity awaiting bariatric surgery. They showed improvement of physical fitness and social interactions after 12 weeks of training compared to controls, without any difference in weight loss. Post-surgical data are not available in this study [13]. A RCT by Kalarchian et al., investigating the impact of pre-surgical lifestyle intervention on weight loss at 6,12 , and 24 months after bariatric surgery showed no difference in weight loss compared to usual care. In addition, they found no effects on post-surgical complications. A limitation of this study is that there were no data available about other outcomes like physical activity or quality of life [14]. Another recent study showed that exercise counseling and using pedometers are effective to increase physical activity during the preoperative period up to 6.5 months after bariatric surgery [15]. None of these studies have included subjects with asthma or other respiratory disorders.
In the present study, we showed that the improvements of ACQ, AQLQ, and 6MWD after PR persisted until 6 months after bariatric surgery. However, there were no differences in the amount of improvements of ACQ and AQLQ after bariatric surgery between patients who performed PR or not.

Despite the small sample size and the descriptive nature of this study, the results suggest that PR is feasible in morbidly obese asthmatics and should be considered for a selected group of patients with uncontrolled asthma before undergoing bariatric surgery. Well-designed randomized controlled trials are needed to confirm these results and the effect on postsurgical complications.

Acknowledgements We thank departments of physiotherapy, psychology, and dietetics with their contribution to this study.

Funding This research was supported by grants from Foundation Research and Development Department of Internal Medicine Sint Franciscus Gasthuis (Stichting Onderzoek en Ontwikkeling Interne Specialismen Sint Franciscus Gasthuis).

Compliance with Ethical Standards

Conflict of Interest The authors declare that they have no conflict of interest.

\section{References}

1. Camargo Jr CA, Weiss ST, Zhang S, et al. Prospective study of body mass index, weight change, and risk of adult-onset asthma in women. Arch Intern Med. 1999;159(21):2582-8.

2. van Huisstede A, Rudolphus A, Castro Cabezas M, et al. Effect of bariatric surgery on asthma control, lung function and bronchial and systemic inflammation in morbidly obese subjects with asthma. Thorax. 2015;70(7):659-67.

3. van Huisstede A, Biter LU, Luitwieler R, et al. Pulmonary function testing and complications of laparoscopic bariatric surgery. Obes Surg. 2013;23(10):1596-603.

4. Singh SJ, ZuWallack RL, Garvey C, et al., American Thoracic Society/European Respiratory Society Task Force on Pulmonary R. Learn from the past and create the future: the 2013 ATS/ERS statement on pulmonary rehabilitation. Eur Respir J. 2013;42(5):1169-74.

5. Juniper EF, Guyatt GH, Cox FM, et al. Development and validation of the mini asthma quality of life questionnaire. Eur Respir J. 1999;14(1):32-8.

6. Juniper EF, O'Byrne PM, Guyatt GH, et al. Development and validation of a questionnaire to measure asthma control. Eur Respir J 1999;14(4):902-7.

7. Laboratories ATSCoPSfCPF. ATS statement: guidelines for the six-minute walk test. Am J Respir Crit Care Med. 2002;166(1):111-7.

8. Ross RM. ATS/ACCP statement on cardiopulmonary exercise testing. Am J Respir Crit Care Med. 2003;167(10):1451. author reply

9. American Thoracic S, European RS. ATS/ERS recommendations for standardized procedures for the online and offline measurement of exhaled lower respiratory nitric oxide and nasal nitric oxide, 2005. Am J Respir Crit Care Med. 2005;171(8):912-30. 
10. Miller MR, Hankinson J, Brusasco V, et al. Standardisation of spirometry. Eur Respir J. 2005;26(2):319-38.

11. Scott HA, Gibson PG, Garg ML, et al. Dietary restriction and exercise improve airway inflammation and clinical outcomes in overweight and obese asthma: a randomized trial. Clin Exp Allergy. 2013;43(1):36-49.

12. Freitas PD, Ferreira PG, Silva AG, et al. The role of exercise in a weight-loss program on clinical control in obese adults with asthma: a RCT. Am J Respir Crit Care Med. 2017;195(1):32-42.
13. Baillot A, Mampuya WM, Dionne IJ, et al. Impacts of supervised exercise training in addition to interdisciplinary lifestyle management in subjects awaiting bariatric surgery: a randomized controlled study. Obes Surg. 2016;26(11):2602-10.

14. Kalarchian MA, Marcus MD, Courcoulas AP, et al. Preoperative lifestyle intervention in bariatric surgery: a randomized clinical trial. Surg Obes Relat Dis. 2016;12(1):180-7.

15. Creel DB, Schuh LM, Reed CA, et al. A randomized trial comparing two interventions to increase physical activity among patients undergoing bariatric surgery. Obesity (Silver Spring). 2016;24(8):1660-8. 